\title{
OPEN Author Correction: First crystal structure of an endo-levanase - the BT1760 from a human gut commensal Bacteroides thetaiotaomicron
}

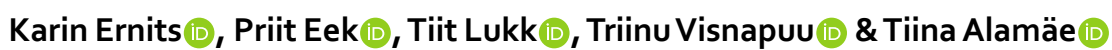

Correction to: Scientific Reports https://doi.org/10.1038/s41598-019-44785-0, published online 11 June 2019

The Supplementary Information file that accompanies this article contains errors.

In the legend of Supplementary Figure S3 where:

"The structure of wild-type endo-levanase (dark blue) is superimposed on the structure of E221A mutant (light blue). Levantetraose (magenta) and water molecules are from the E221A structure. Fructose-binding subsites, catalytic amino acids, two alternate conformations of Gln239, and C2, O6, and C6 from $\beta$-2,6-linkage are designated."

should read:

"The structure of wild-type endo-levanase (light blue) is superimposed on the structure of E221A mutant (dark blue). Levantetraose (magenta) and water molecules are from the E221A structure. Fructose-binding subsites, catalytic amino acids, two alternate conformations of Gln239, as well as C2, O6 and C6 from $\beta$-2,6-linkage are designated."

In the legend of Supplementary Figure S5 where:

"The images were not digitally modified except for applying grayscale mode, the originals are presented in Supplementary Figure S5."

should read:

"The images were not digitally modified except for applying grayscale mode, the originals are presented in Supplementary Figure S6."

(c) (i) Open Access This article is licensed under a Creative Commons Attribution 4.0 International License, which permits use, sharing, adaptation, distribution and reproduction in any medium or format, as long as you give appropriate credit to the original author(s) and the source, provide a link to the Creative Commons license, and indicate if changes were made. The images or other third party material in this article are included in the article's Creative Commons license, unless indicated otherwise in a credit line to the material. If material is not included in the article's Creative Commons license and your intended use is not permitted by statutory regulation or exceeds the permitted use, you will need to obtain permission directly from the copyright holder. To view a copy of this license, visit http://creativecommons.org/licenses/by/4.0/.

(C) The Author(s) 2019 